Boletim IG. Instituto de Geociências, USP. V. $4: 39-46 \cdots 1973$

\title{
O BATÓLITO QUARTZO-SIENITICO DA SERRA DA BAIXA VERDE, PERNAMBUCO
}

Por

\author{
Georg Robert Sadowski
}

Departamento de Geologia Geral

\section{ABSTRACT}

On the limits of the Pernambuco and Paraiba States, Brazil, occurs a quartz syenitic body with an outcrop area of about $400 \mathrm{~km}^{2}$. At its East side lies a probably relative granite and both are apparently intruded in schists of the Cachoeirinha and Uaua Groups. The area, localized in the Caririan transversal Zone wich is situated between the large Pernambuco and $\mathrm{Pa}$ tos lineaments, was cut by several secondary transcurrent faults and associated shear and tension fractures. The author supposes that the massif belongs to an assemblage of similar rock types intruded in and on the proximities of the transversal zone.

\section{RESUMO}

$\mathrm{Na}$ divisa entre os Estados de Pernambuco e Paraiba ocorre um corpo quartzo sienítico abrangendo uma área de exposição de aproximadamente $400 \mathrm{~km}^{2}$. Encontra-se ladeado por um granito provavelmente aparentado e está encaixado nos xistos dos grupos Uauá e Cachoeirinha. A área, localizada na "zona transversal" Caririana entre os lineamentos de Patos e Pernambuco, encontra-se cortada por falhas transcorrentes secundárias, e fraturas de tração e de cisalhamento associadas aos lineamentos citados. $\mathbf{O}$ autor supõe que este maciço faz parte de um conjunto de rochas similares introduzidas no episódio tardio do Ciclo Brasiliano, dentro e nas proximidades da zona transversal.

\section{INTRODUÇÃO}

Na Zona Transversal de EBERT (1958) situase uma série de corpos sieníticos e granitóides denominados Catingueira por ALMEIDA ET AL. (1967) nas proximidades do Lineamento de Patos e Moderna por SANTOS (1971) nas vizinhanças do Lineamento de Pernambuco.

COUTINHO E VANDOROS (1966) descreveram com um certo detalhe um destes corpos situados na área de S. Gonçalo na Paraíba, atribuindo-lhe uma idade de 610 m.a..

BARBOSA ET AL. (1971) mapearam uma série de corpos que qualificaram como sieníticos cientro da Zona Transversal, sem no entanto os descrever com pormenores.
O maior desses corpos é um batólito exposto em mais de $400 \mathrm{~km}^{2}$ na divisa entre os Estados de Pernambuco e Paraíba. Tivemos a oportunidade de percorrer aproximadamente $3 / 4$ de sua área, bem como suas encaixantes a $\mathrm{E}, \mathrm{W}$ e $\mathrm{S}$. Aqui apresentamos os resultados das observação de campo, complementados por estudos fotogeológicos petrográficos e geocronológicos e tentamos definir o caráter tectônico do maciço e a sua eventual relação com o corpo estudado por COUTINHO e VANDOROS.

\section{GEOLOGIA REGIONAL}

Localizaçāo estratigráfica - $\mathrm{O}$ maciço estudado situa-se na zona de metamórficos denominados Uauá e Cachoeirinha por BARBOSA 


\section{MAPA GEOLÓGICO DA SERRA DA BAIXA VERDE - PE.}

FÒLHA BASE: SUDENE; SERRA TALHADA - PERNAMBUCO

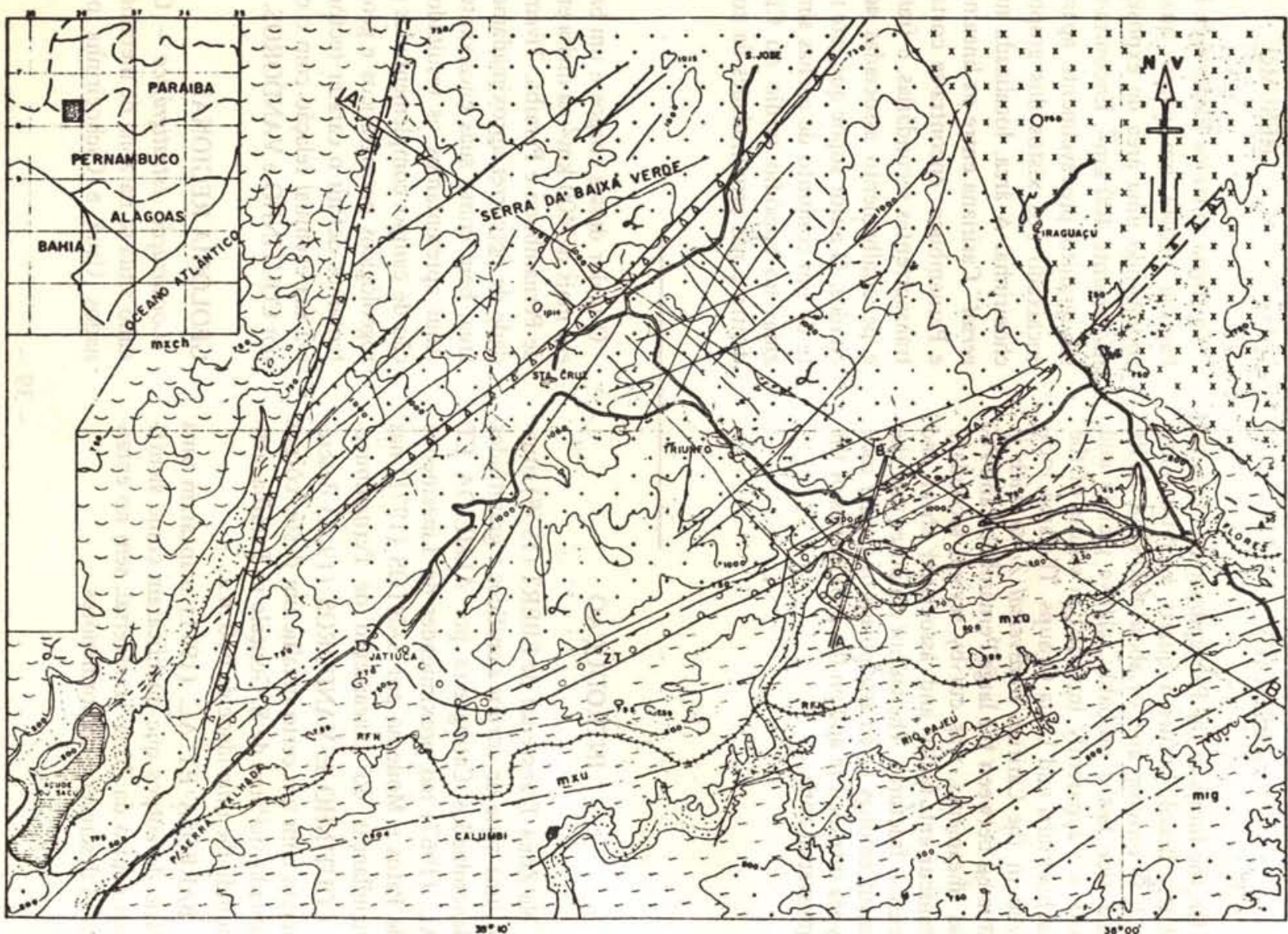

LEGENDA

QUATERNÁRIO

SEDIMENTOS ALUVIONARES

PRE' - DEVONIANO

II MILONITOS E CATACLASITOS EM GERAL

PRÉ-CAMBRIANO

\begin{tabular}{|c|c|}
\hline 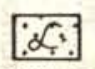 & $x^{2} y^{2} x$ \\
\hline SIENITO & GRANITO \\
\hline ; & $\therefore 9$ \\
\hline
\end{tabular}

MiCAXISTOS $(m x)$ dOS GRUPOS UAUA E CA CHOEIRINHA E MIGMATITOS (mig)

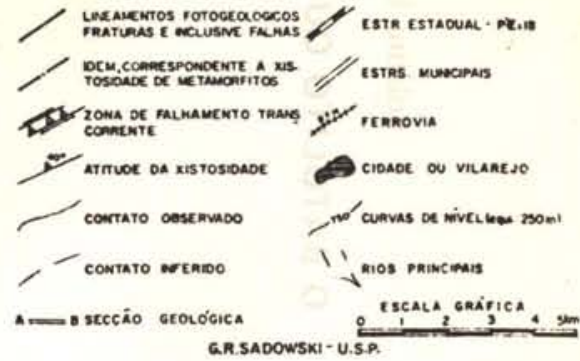




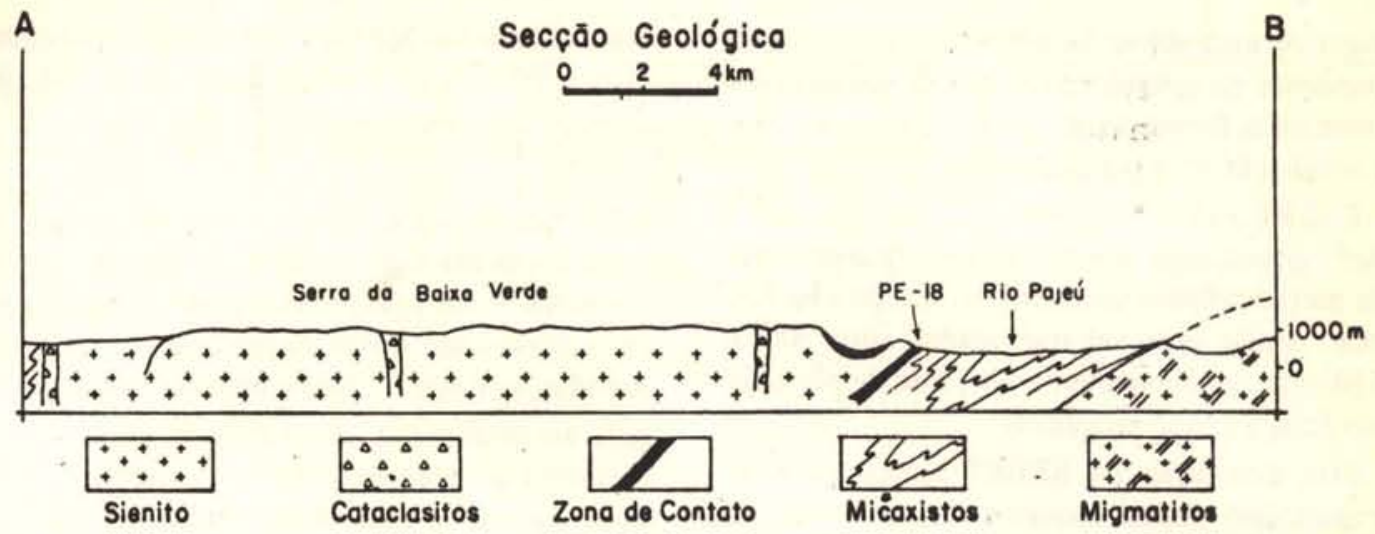

(1971). Na área, os xistos do Grupo Cachoeirinha repousam em sinclinal sobre ectinitos do Grupo Uauá. A Sudeste da área mapeada, as rochas do Grupo Uauá apresentam-se migmatizadas com estrutura bandada.

Comparando os mapeamentos executados por EBERT et AL. (1971) na área da Borborema, e os realizados por BARBOSA et AL. (1971), notamos que os mica-xistos Cachoeirinha coincidem com os xistos Seridó de EBERT e que a Formação Parelhas deste autor está contida no Grupo Uauá. EBERT (1971) considera a Formação Parelhas como pertencente ao Complexo Caicó sotoposto por disconformidade ao Grupo Seridó dentro da sequência précambriana do Cariri.

Aspectos Estruturais - A Zona Transversal está limitada ao norte pelo linearnento de Patos e ao sul pelo lineamento de Pernambuco. No mapa geológico do Projeto Cobre (BARBOSA et AL., 1971), correspondente à Geologia do Médio S. Francisco notamos que as estruturas apresentam disposição em S. Durante nossos trabalhos, notamos falhas direcionais secundárias de mais de $25 \mathrm{~km}$ de comprimento e faixas cataclásticas da ordem de $500 \mathrm{~m}$ de espessura com altitudes $\mathrm{N} 15$ a $50 \mathrm{E}$, subverticais e com estrias sub horizontais tais como a falha de Sta. Cruz. Associadas ocorrem fraturas de tração NW algumas preenchidas por diques de diabásio. Tais ocorrências denotariam movimentação dextral das falhas de Patos e Pernambuco com rotação resistente anti-horária do bloco central dando cisalhamentos sinistrais secundários de direção NE e alívios segundo esta direção resultando partição NW.
As falhas de Patos e Pernambuco não são contínuas (SANTOS 1971, EBERT 1971) apresentando-se granitizadas em alguns trechos. Os sedimentos das chapadas vizinhas não apresentam indícios de movimentos direcionais mas foram falhados normalmente. Tal conjunto de estruturas faz pensar que estes falhamentos são extremamente antigos, tendo se reativado localmente durante a evolução da plataforma.

Aspectos Geomorfológicos - Na área mapeada notamos encaixe nítido da drenagem em raturas e lineamentos geológicos. A espessura lo solo é menor que $1,5 \mathrm{~m}$ em média, com exceção das vertentes onde podemos atingir mais de $8 \mathrm{~m}$ em solo residual. $O$ fino capeamento de solos expõe as estruturas à superfície facilitando assim a sua observação.

Localizamos duas superfícies de erosão, a primeira, a mais notável, é a Superfície Pós-Gondwana de KING (1956) representada localmente pelo topo arrasado da Serra da Baixa Verde, que se sobressai com altitudes, de 1.000 a $1.100 \mathrm{~m}$. A segunda situada entre 500 a $600 \mathrm{~m}$ foi denominada Superfície Soledade por MEUNIER (1961).

Geocronologia - ALMEIDA et AL. (1968) apresentaram uma subdivisão do Pré-Cambriano do Nordeste com base em trabalhos realizados por outros autores anteriormente e em 80 determinações geocronológicas. Cinquenta destas, foram dedicadas ao espaço Caririano. Consideram que anfibolitos e metagabros, intrusivos na Formação Caıco apresentam idades mínimas de $1860 \pm 83$ m.a. e $1470 \pm 70$ m.a.. Para o Grupo denominado Ceará por estes autores, que incluiria o Grupo Seridó de EBERT, 
sugerem uma idade de 640 a 530 m.a., correspondente ao episódio principal da orogenia Caririana e a formação de granitos, granodioritos e sienitos tardi- e pós tectónicos.

EBERT (1971) apresenta 30 datações K40/ $\mathrm{Ar}^{40}$ concluindo que houve uma fase principal de metamorfismo dinâmico no mínimo há 850 m.a., sendo provável que idades entre $450 \mathrm{e}$ 550 m.a. correspondam a uma fase de plutonismo final do ciclo orogênico.

Esta conclusão de EBERT aproxima-se do exposto no último esquema de subdivisão do pré-cambriano proposto por ALMEIDA (1971) ou seja da divisão do Ciclo Brasiliano em dois estágios, um tardio de 570 a 620 m.a. e outro precoce entre 620 e 900 m.a..

No que tange ao maciço da Baixa Verde determinações geocronológicas pelo método $\mathrm{K}^{40}$ / $\mathrm{Ar}^{40}$ num feldspato deram uma idade de $\mathbf{5 7 0}$ m.a., o que permite considerá-lo no estágio tardio do Ciclo Brasiliano, tal como o do Maciço de S. Gonçalo (COUTINHO e VANDOROS).

\section{GEOLOGIA DA ÅREA DO MACIÇO}

Relações de contato - Como já observamos acima, o maciço da Serra da Baixa Verde está encaixado em rochas xistosas, tendo o Grupo Cachoeirinha no seu flanco noroeste e os metamorfitos do Grupo Uauá na sua borda restante. A área estudada no campo, pelo autor, envolveu somente o corpo intrusivo e seus contatos na faixa sul, não tendo sido pesquisadas com detalhe, por dificuldades de acesso na ocasião. as relações de contato com o Grupo Cachoeirinha. Observações em fotografias aéreas associadas a algumas evidências de campo revelam um contato por falhamento transcorrente com este último Grupo.

$\mathrm{Na}$ zona de contato do maciço sienítico com o Grupo Uauá, este apresenta uma faixa feldspatizada com notável enriquecimento em microclina. Outrossim, notamos intercalações sieníticas intrusivas ou encaixadas entre falhas, dentro das metamórficas, paralelas em direção à xistosidade.

Em alguns locais, nos cortes da rodovia PE-18 e proximidades, as relaçōes de contato são pouco claras à primeira vista, por apresentar a in- trusiva uma lineação de máficos concordantes com a direção de gnaissificação da auréola de contato com direção N70W e EW.

Em quase toda a faixa sul do contato o mica xisto apresenta xistosidade mergulhando contra o maciço e, nas suas proximidades, já nas faixas microclinizadas, temos mergulhos sub-verticais notados na foliação, frequentemente obliterada pela recristalização. Em alguns pontos, temos inclusões orientadas de máficos na zona de contato, que verificamos serem restos de mica xistos alcalinizados, imersos em matriz sienítica.

$\mathrm{Na}$ região em que o maciço apresentou composição próxima a granito, não localizamos zonas de feldspatização da encaixante mas apenas uma incipiente turmalinização.

Em virtude da área de exposição do pluton abranger mais de $100 \mathrm{~km}^{2}$ conforme podemos verificar no mapa, podemos classificá-lo como batólito, segundo DALY (1932).

Litologia - Mica xistos - Os mica xistos estudados em lâmina são os do Grupo Uauá. Possuem intercalações de camadas quartzíticas centimétricas concordantes com a xistosidade e que em certas circunstâncias favorecem boa visualização das estruturas

Sua coloração é cinza escura e a granulação de média a fina. No que tange a uma definição de fácies de metamorfismo constatamos a presença de biotita e muscovita bem cristalizadas juntamente com traços de plagioclásio, não tendo sido possível defini-lo. Dada a sua composição modal (Vide tabela n! 1) estas rochas foram classificadas como biotita-muscovita-quartzo xistos. Nas proximidades de corpos graníti$\cos$ menores intrusivos nestes xistos, foi observada pequena quantidade de turmalina.

Gnaisses de transição - Formando uma auréola na borda do corpo intrusivo de composição sienítica, temos uma zona de microclina gnaisses com biotita e hornblenda.

A textura é granoblástica orientada, apresentando-se, às vezes totalmente granular e sem orientação visível. A hornblenda está associada com a biotita e não foi encontrada a muscovita, presente no xistos. A fácies de metamorfis- 
Tabela n: 1 - Médias Aritméticas das Análises Modais das Rochas Estudadas

\begin{tabular}{|c|c|c|c|c|c|c|}
\hline Rocha & +3 & Rocha hibri- & Gnaisse de & $3 x$ & 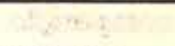 & 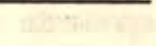 \\
\hline Mineral & Micaxisto & dade borda & transição & & Sienito & Granito \\
\hline Quartzo & $55,1 \%$ & $9,8 \%$ & $28,5 \%$ & & $5,4 \%$ & $19,4 \%$ \\
\hline Microclina & ............ & 60,6 & 62,0 & & 68,9 & 51,6 \\
\hline Plagioclásio & $\mathbf{x x}$ & 11,4 & 0,8 & & $11,5(\mathrm{Ab})$ & $8,0(\mathrm{Ab})$ \\
\hline Hornblenda & ............ & .......... & 4,0 & & ............ & ........... \\
\hline Anfibólio sódico & ............ & 3,0 & ............ & & 1,1 & ............ \\
\hline Augita sódica & ............ & 8,3 & ............ & & 11,5 & $16,3(\mathrm{Ca})$ \\
\hline Muscovita & 28,0 & 2,0 & (........... & & (............ & ............ \\
\hline Biotita & 13,8 & 0,5 & 4,0 & & (........... & 1,3 \\
\hline Apatita & ........... & 1,0 & ........... & & 0,4 & 0,2 \\
\hline Titanita & ............ & 1,4 & (........... & & 0,5 & 0,2 \\
\hline Zircão & ............ & .......... & 0,2 & & 0,1 & 0,4 \\
\hline Opacos & 3,19 & 2,0 & 0,4 & & 0,5 & 1,8 \\
\hline Carbonatos secundários & ............ & $\ldots \ldots \ldots$ & 0,1 & &.$x x$ & ............. . \\
\hline
\end{tabular}

mo correspondente pode ser definida como anfibolito. 0 microclínio é hipidiomorfo em forma de porfiroblastos pertíticos, e com geminação em grade. É frequentemente fraturado nas bordas com fissuras preenchidas por carbonatos secundários (textura mortar). Este aspecto caracteriza uma cataclase posterior a sua cristalização. Outros minerais como biotita e oligoclásio também se apresentam fraturados. Os grãos de quartzo apresentam extinção ondulante. Estes gnaisses formam uma faixa de aproximadamente $800 \mathrm{~m}$ de largura na horizontal apresentando características variáveis conforme nos aproximamos da intrusão. A algumas dezenas de metros da intrusão encontramos pequenas lentes de máficos, centimétricas e orientadas nas quais, o anfibólio sódico, que também ocorre na ígnea, aparece associado com a biotita ocorrendo também uma associação da microclina com o quartzo. Neste local, a gnaissificação da matriz clara está obliterada apresentando a rocha uma textura granular.

A passagem quase total de biotita para anfibólio e a diminuição de quartzo com aumento de microclínio sugerem uma zona de fenitizaçâo.

Sienitos - Quanto à rocha intrusiva na parte oeste do maciço, foi classificada como quartzo sienito segundo a classificação de NIGGLI e sienito segundo JOHANNSEN em base de análises modais efetuadas em quatro amostras co- letadas em diferentes locais do maciço. Sua textura é fanerítica média dentro do corpo maior e fina nos corpos menores. A porcentagem de quartzo de amostra para amostra variou de $8,8 \%$ a $1,4 \%$. Segundo JOHANNSEN, a presença de augita sódica favorece a sua classificação como sienito. Sua composição mineralógica modal como a de outras rochas citadas no trabalho em questão se desprende da tabela n? 1.

O anfibólio azulado nesta área, tanto nas rochas da zona de transição como no sienito, foi definido como sendo do tipo sódico. Apresenta-se em forma de agulhas ou em massas de cor azulada, com o seguinte pleocroismo:

$\mathrm{X}$ - verde claro $\mathrm{Y}$ - violeta claro $\mathrm{Z}$ - azul claro

A existência deste anfibólio com um ângulo $Z \hat{c}$ de $30^{\circ}$, maior do que o encontrado usualmente em minerais análogos da série Eckêrmanita/Arfvedsonita, foi constatada também por COUTINHO e VANDOROS (1966) em um sienito semelhante situado a $100 \mathrm{~km}$ da nossa área, em S. Gonçalo no Estado do Paraíba.

Estes autores, que inclusive realizaram análises químicas dos minerais, consideraram-no como richterita.

Quanto a efeitos de cataclase, notamos os mesmos já citados nos gnaisses de transição.

Granitos - A parte leste da intrusão pelo que pudemos concluir através do exame de campo 
e posterior constatação das análises modais, apresenta composição granítica. Segundo os critérios de JOHANNSEN e NIGGLI situa-se entre os granitos alcalinos. É uma rocha de textura fanerítica a média com fenocristais de 1 a $2 \mathrm{~mm}$ de microclínio, levemente orientados com evidências de esmagamento nas bordas. 0 plagioclásio evidenciou ser albita An $0_{8}$ apresentando frequentemente geminações Carlsbad e lei da albita combinadas. $\mathrm{O}$ quartzo apresenta com frequência, extinção ondulante. 0 piroxênio presente é augita. Não encontramos anfibólio como no sienito mas, biotita.

Discussão - 0 batólito apresenta uma composição granítica a leste e sienítica a oeste. A delimitação entre estas duas composições somente poderá ser precisada com exatidão após amostragem detalhada. No momento, supomos serem fases diferenciadas de um mesmo magma.

A existência de zonas de microclina gnaisses na borda sul do corpo sienítico sugere a existência de uma auréola de contato provavelmente do tipo fenítico, como já observamos acima.

\section{Estruturas}

$\mathrm{Na}$ área estudada, a xistosidade apresenta em média valores situados entre $\mathrm{N} 70 \mathrm{OW}^{\mathrm{W}}$ e $\mathrm{N} 70^{\circ} \mathrm{E}$ com mergulhos dominantes para norte, estas são também as direções genéricas dos eixos de dobramentos medidos nos mica xistos. No caso, são os planos de xistosidade que estão corrugados e dobrados. Estes planos de xistosidade são proporcionados especialmente pela orientação das micas.

Os dobramentos localizados na estrada entre Iraguaçu e Flores apresentam-se assimétricos com vergência para sul. Nas proximidades das intrusões menores de sienito a xistosidade contorna estes corpos tendendo a cair para fora nas extremidades leste e oeste dos mesmos. De uma forma geral a xistosidade cai para norte com ângulos cujo valor oscila por volta de $40^{\circ}$ tornando-se maior conforme nos aproximamos do corpo intrusivo.

Os gnaisses de contato que também formam auréolas ao redor dos corpos menores de intrusão, apresentam atitudes similares às dos xistos apresentando no entanto, junto à intrusão mergulhos sub verticais.

A passagem de gnaisses para xistos é de certa forma intermitente e gradual, e nas proximidades do corpo de intrusão maior a alternância de línguas ou faixas sieníticas que se intercalam nos mica xistos ou nos gnaisses ocasiona dificuldades na distinção entre os corpos.

No maciço intrusivo as estruturas mais marcantes são:

- a lineação proporcionada pelos máficos com direção média N70oW;

- zonas de cataclasitos incluindo milonitos e estrias, evidenciando em alguns pontos o predomínio de movimentos horizontais;

- corpos sieníticos de granulação fina a média fanerítica com caráter hipoabissal, concordantes com a xistosidade e que seriam prolongamentos do corpo maior;

- xenólitos de mica xistos digeridos parcialmente ou alcalinizados.

Grandes falhas transcorrentes cortam o maciço, como a falha sinistral que passa nos arredores de Sta. Cruz.

\section{COMPARAÇÃO COM O MACIÇO DE S. GONÇALO}

0 maciço de $\mathrm{S}$. Gonçalo também apresenta uma lineação proeminente dos seus máficos cuja direção é N80W e uma composição modal semelhante à da Serra da Baixa Verde, conforme podemos constatar na tabela a seguir:

Tabela n? 2 Comparação de análises modais entre os maciços de S. Gonçaloe da Baixa Verde.

\begin{tabular}{|c|c|c|c|}
\hline \multirow{2}{*}{$\begin{array}{l}\text { Minerais } \\
\text { Quartzo }\end{array}$} & \multicolumn{2}{|c|}{ S. Gonçalo } & \multirow{2}{*}{$\begin{array}{c}\text { Baixa Verde } \\
5,4\end{array}$} \\
\hline & 2,2 & 0 & \\
\hline Feldspatos & 71,4 & 83,0 & 80,4 \\
\hline Micr.Plag. & & & \\
\hline Richterita & 19,4 & 12,0 & 1,1 \\
\hline Augita Sódica & 1,9 & 3,1 & 11,5 \\
\hline Acessórios & $0, x$ & $0, x$ & $\begin{array}{l}\text { resto, incluindo } \\
\text { carbonatos se - } \\
\text { cundários. }\end{array}$ \\
\hline
\end{tabular}


f) Supomos que seja bem provável uma correlação estreita com os afloramentos de sienitos semelhantes que ocorrem em areas tais como o de S. Gonçalo no Paraíba, e os de Umã, Pajeú e Serra do Padre. Para confirmar tal idéia, seriam necessários estudos complementares em grande escala, abrangendo todas as ocorrências como as do tipo Moderna de SANTOS (1971) e Catingueira de ALMEIDA et AL. (1967).

\section{AGRADECIMENTOS}

Ao professor Doutor Yociteru Hasui, pelas valiosas sugestões e revisão cuidadosa do texto. Ao professor Doutor Adolpho José Melfi orientador da dissertação de mestrado do autor, durante a qual se realizou parte dos trabalhos. Ao geólogo Woldemar Iwanuch, estagiário do Laboratório do Centro de Pesquisas Geocronológicas da Universidade de São Paulo pelas datações efetuadas em amostras do maciço estudado. À firma Vasp Aerofotogrametria S/A., que possibilitou a execução dos trabalhos de campo e foto interpretação.

\section{BIBLIOGRAFIA}

ALMEIDA, F.F.M. (1969) - "Diferenciação tectônica da Plataforma Brasileira" - XXIII C.B.G. - pg. 29 a 46.

ALMEIDA, F.F.M. (1971) - “Geochronological Division of the Pré-Cambrian of South America" - Rev. Bras. Geoc. - vol. 1, n. 1, pg. 13 a 21.

ALMEIDA ET AL (1968) - "Radiometric age determinations from Northern Brazil" Bol. Soc. Bras. Geol. 17, pg. 3 a 14, 3 fig.

ALMEIDA ET AL (1967) - "Review on Granitic rocks of Northeast South America" IUGS/UNESCO SYMPOSIUM IN RECIFE $-41 \mathrm{pg}$.

BARBOSA, O. ET AL (1970) - “Geologia Econômica da Região do Médio São Francisco" - Bol. n! 140 DFPM - DNPM.

BEURLBN, K. (1970) - “Geologie von Brasitien'" - Gebr. Borntrager Verlag - Berlin
EBERT, H. (1969) - "Geologia do Alto Seridó". nota explicativa a folha geológica de Currais Novos - 1:250.000. SUDENE (Recife) - Série Geologia Regional.

EBERT, H. (1970) - "The Pré-Cambrian geology of the 'Borborema' Belt" - Bd. 59, Heft 3 - pg. 1292 a 1326.

MARMO, V. (1971) - "Granite Petrology..." Elsevier Publ. Co. Ist. edition - NY.

RAGUIN, E. (1946) - "Géologie du Granite" - Masson et Cie. - Paris.

SANTOS, E.J. dos (1971) - "As feições estruturais da folha Arco Verde, Pernambuco..." Min. e Met. vol. LIII, no 313, pg. 35 a 40.

VANDOROS, P. e COUTINHO, M.V. (1966) "Estudo Geológico e Geocronológico da Área de S. Gonçalo, Paraiba" - Rev. da S.B.G.. 